\title{
Esboços e projetos da sociedade empreendedora: mundo conexionista, sociabilidade e consumo'
}

\section{Drafts and projects from the entrepreneurial society: connectionist world, sociability and consumption}

\author{
Vander Casaqui \\ Professor do Programa de Pós-Graduação em Comunicação e Práticas de Consumo (PPGCOM-ESPM). Doutor em Ciências da \\ Comunicação pela Universidade de São Paulo. \\ <vcasaqui@yahoo.com.br>
}

\section{RESUMO}

Este artigo tem como tema a cultura empreendedora, compreendida como processo comunicacional por meio doestudo do Projeto Draft;ou, segundoas palavras do próprio projeto, trata-se da análise da Cultura Maker, ou os "novos empreendedores brasileiros". O objeto de estudo é uma plataforma digital que dá visibilidade a iniciativas de empreendedorismo, empreendedorismo social, novos negócios, que oscila entre uma estética jornalística e conteúdos patrocinados por grandes corporações. Em pauta, está um Brasil editado pela visão da sociedade empreendedora (Drucker, 2011). Dentre os temas desenvolvidos, estão: a relação entre projetos de nação, cultura empreendedora e o espírito do capitalismo (Boltanski e Chiapello, 2009); os significados do consumo, as formas de sociabilidade e os modelos de cultura (Morin, 2007) construídos no ambiente do Projeto Draft. O método da pesquisa se fundamenta na proposta de análise crítica de discurso de Fairclough (2001).

Palavras-chave: Cultura empreendedora. Comunicação e consumo. Discurso.

\begin{abstract}
This article focuses on the entrepreneurial culture, understood as communication process by the analysis of the Draft Project; or, in the words of the project itself, it is the analysis of the "Maker Culture", or the "new Brazilian entrepreneurs". The object of study is a digital platform that gives visibility to entrepreneurship initiatives, social entrepreneurship, and new businesses, ranging from a journalistic aesthetic to the sponsored content by large corporations. At issue is a Brazil edited by the vision of "entrepreneurial society" (Drucker, 2011). Among the themes developed are: the asrelationship between national projects, entrepreneurial culture and the spirit of capitalism (Boltanski; Chiapello, 2009); the meanings of consumption, forms of sociability and culture models (Morin, 2007) built on the Draft Project environment. The research method is based on the critical discourse analysis of Fairclough (2001).
\end{abstract}

Keywords: Cultura empreendedora. Comunicação e consumo. Discurso.

\section{Introdução}

"Bem-vindo ao novo mundo. Da economia criativa, das empresas líquidas,

1 Trabalho apresentado no $24^{\circ}$ Encontro Anual da Compós - Brasília: UNB/UCB, realizado de 9 a 12 de junho de 2015. 
das relações de trabalho efêmeras, da atração de talentos para causas, e não para cargos". Do vídeo de divulgação do Projeto Draft (Projeto Draft, 2013), que compõe o objeto deste estudo, extraímos esse pequeno panorama do imaginário social e dos lugares comuns que permeiam aquilo que reconhecemos como a cultura empreendedora correspondente ao terceiro espírito do capitalismo, de acordo com a teoria de Boltanski e Chiapello (2009). Entre outras coisas, fica evidente o tom eufórico, a celebração indissociável da visão de mundo expressa pela plataforma, em que as múltiplas expressões de iniciativas empreendedoras são celebradas como sintomas de um admirável mundo novo que chegou ao Brasil para ficar. Ecos de pesquisas de tendências, de teorias apocalípticointegradas, de utopias pragmáticas podem ser identificados - que dialogam, entre outras coisas, com o imaginário da Geração Y, ou Geração Millenials, festejada por pesquisas como as desenvolvidas pela agência brasileira Box1824, dentre as quais destacamos os projetos Sonho Brasileiro (2011) - autointitulado estudo sobre o Brasil e o futuro a partir da perspectiva do jovem de 18 a 24 anos - e o posterior vídeo de divulgação de pesquisa (em tom de manifesto) Allworkandall play (2012).

Este trabalho é uma proposta de mergulho reflexivo nesse mundo editado, por essa cultura que ganha força em nossos dias e se difunde por uma imensa gama de discursos, que tem em comum essa celebração do presente e o exercício, frequentemente precário, da futurologia - não como ciência exatamente, mas principalmente como convocação (Prado, 2013). Eis uma expressão da utopia da sociedade empreendedora, como imaginada por Peter Drucker (2011), um dos autores mais destacados do campo do marketing e do empreendedorismo. Sendo um projeto de sociedade, obviamente implica uma doutrina relativa às formas de sociabilidade, ao papel a ser exercido pelos indivíduos nesse lugar planejado para o futuro.

Sarlo (2004) discute sobre a imaginação técnica em Buenos Aires das primeiras décadas do século $\mathrm{XX}$, por meio da análise do diário Crítica, em seu papel de divulgação científica, dos avanços tecnológicos da época, imersa no espírito da modernidade. Em sua visão, "[...] a difusão desses novos saberes tem como uma de suas condições a forte presença de um elemento fantasioso que nomeia o futuro e o projeta hipoteticamente, não somente a partir da ciência, mas desde os mitos da ciência" (p. 11, tradução nossa)2. Nesse contexto, emerge a figura do inventor, o modelo de cultura da modernidade, "[...] um

2 No original: "[...] ladifusión de esos saberes nuevostiene como una de sus condiciones la presencia fuerte de un elemento fantasioso que nombrael futuro y lohipotetiza no sólo desde laciencia sino desde los mitos de laciencia". 
tipo social em todo o ocidente, especialmente nos Estados Unidos"3 (p. 89), que "[...] se implanta na imaginação dos jornalistas, dos comerciantes e dos artesãos habilidosos" (p. 17, tradução nossa) ${ }^{4}$. A autora extrai desse interessante estudo os "perfis da modernidade na Argentina"5 (Sarlo), ou seja, os sintomas do imaginário social desse período estudado. Destacamos uma frase que, relacionada com a modernidade, mantém relação estreita com o nosso tempo, especialmente com o objeto deste trabalho: "[...] na modernidade, o presente exibe sua força e não sua debilidade provisória, já que nele estão contidas as promessas do futuro" (p. 87, tradução nossa) ${ }^{6}$. É nesse jogo de temporalidades que se estabelece o Projeto Draft, entre a divulgação do que já está e do projeto global do que poderia vir a ser, em alinhamento com o imaginário derivado da cultura empreendedora.

Guardadas as devidas proporções entre os dois estudos e as diferenças de cenários, de épocas, entre outros elementos, podemos extrair da obra de Beatriz Sarlo algumas questões a serem transpostas para este trabalho. A começar pela questão da imaginação técnica, que é traduzida nas projeções de futuro, por vezes fantasiosas, por mais que soem verossímeis e se pautem por informações, por evidências, por traços de uma suposta ciência. Outra contribuição a ser extraída está na atualização da imagem do inventor para o empreendedor, o responsável na contemporaneidade pela inovação, seja ela aplicada a novos negócios, a empreendimentos sociais, a novidades inseridas no ambiente interno de organizações. Se há certa atenuação desse imaginário em relação à materialidade das tecnologias, a questão técnica se aplica à expertise empreendedora e sua capacidade, hipotética ou ficcionalizada, de mudar o mundo, transformar relações, inventar o futuro - como está expresso na missão do Projeto Draft (Projeto Draft, 2015):

Nosso material de trabalho são os desbravadores, talentos que não vieram ao mundo a passeio. Nossos personagens são os transformadores que tem uma obsessão e que trabalham para uma causa: inventar o futuro. Pessoas que se dedicam a gerar mais e melhores soluções para o planeta e para a sociedade. E que desejam se realizar como profissionais e como seres humanos nesse processo.

3 No original: "[...] un tipo social en todo occidente, especialmente en Estados Unidos".

4 No original: "[...] se implanta enlaimaginación de los periodistas, los comerciantes y losartesanos habilidosos".

5 No original: "perfiles de lamodernidadenla Argentina".

6 No original: "Enlamodernidad, el presente exhibesufuerza y no sudebilidad provisional, ya que enélestáncontenidaslaspromesasdel futuro". 
Nesse pequeno trecho da carta de intenções do Draft, além da grandiloquência em torno do papel social (Dahrendorf, 2012) atribuído aos seus personagens, fica evidente o delineamento de um perfil moral, que alia visão de mundo, cotidiano e trabalho. Algo já identificado e discutido, no cenário capitalista de sua época, por Max Weber (2004), e cuja herança é recuperada pela teoria do novo espírito do capitalismo, de Boltanski e Chiapello (2009). Essa ideologia tem como eixo a figura do empreendedor; da mesma forma que Sarlo identifica na difusão científica e tecnológica observada uma ausência de categorização precisa, que faz caber uma gama bastante ampla e heterogênea sob o guarda-chuva da invenção, o Projeto Draft, visto na totalidade, parece representar um continuum, o anúncio de um novo mundo do século XXI concebido pela sociedade empreendedora, que é profetizado "como mais próximo do que efetivamente está" (Sarlo, 2004, p. 93, tradução nossa).

Notícias do admirável mundo conexionista e o país de empreendedores

De acordocom BoltanskieChiapello, a experiência do mundo conexionista é perturbadora, em decorrência dos conflitos da condição humana em um mundo flexível, "[...] em que os seres se modificam ao sabor das situações que encontram"(2009, p. 420). Esseé o domínio do homem conexionista, o sujeito que identificamos com o imaginário de parte dos projetos de empreendedorismo social tratados em nossa pesquisa, como o Imagina na Copa, discutido em trabalho anterior (CASAQUI, 2014). Um dos argumentos centrais da tese sobre o novo espírito do capitalismo defende que "[...] a reestruturação do capitalismo associou-se a cooptação da figura da rede" (Boltanski e Chiapello, 2009, p. 455). O espírito do capitalismo corresponde às lógicas de justificação que oferecem legitimidade ao sistema e promovem o engajamento, na rearticulação de sua retórica a partir das formulações críticas de seus opositores. Dessa forma, a mítica em torno do empreendedor é promovida como a redenção ante as históricas mazelas do mundo do trabalho, ante as dissonâncias com o espírito libertário juvenil que ganhou força no contexto da contracultura da década de 1960, ante a separação entre trabalho e lazer, entre atividade laboral e felicidade.

Como contraponto a esse cenário anterior, emerge a imagem contemporânea do homem conexionista, adaptado ao trabalho em redes e à flexibilização das relações laborais, identificado com a indústria criativa, com o espírito empreendedor, com a cultura globalizada, com as tecnologias digitais 
como ambiente de sua atividade. Como anuncia, em tom de manifesto, a apresentação do Projeto Draft:

\begin{abstract}
Nossos melhores talentos não buscam mais um emprego de longo prazo numa grande empresa - eles querem se conectar a projetos que durem o tempo justo numa empresa ágil. [Que, em geral, eles mesmos fundam]. Eles não entram num mercado para seguir regras - mas para reinventá-las, testá-las, melhorá-las. Eles não querem ser funcionários. E nem fazem questão de ter funcionários [...]. Também aprendemos com os Makers que não é possível empreender sozinho. Que vivemos em rede. Que juntos, conectados, trocando, compartilhando, somos mais fortes, mais inteligentes, mais criativos - e é assim que realizamos mais e melhor (Projeto Draft, 2015).
\end{abstract}

Esse personagem tem como característica o uso estratégico das relações, a atuação que desloca comportamentos outrora identificados com a amizade para outros contextos, em que as atividades de conexão podem resultar em vantagens financeiras (p. 460). Em síntese, o cenário em torno do homem conexionista é o da mercantilização das relações, dos projetos comunicacionais que se oferecem como plataforma de negócios, ao darem visibilidade para outros sujeitos e iniciativas, como é o caso do Projeto Draft, que promove as ações da sociedade empreendedora brasileira e serve de ambiente para o investimento de marcas. Em sua plataforma encontramos conteúdos identificados com grandes corporações, como é o caso da Natura (produtos de beleza), patrocinadora do portal como um todo; HP / Intel (ramo de informática) e Tecnisa (construtora), patrocinadoras de conteúdos específicos - entre outras marcas presentes nesse mundo concebido como projeto editorial, que em parte dissimula sua função de negócios por meio de notícias do campo do empreendedorismo.

A cultura empreendedora parece se afirmar como o grande paradigma atual, a partir do qual há um processo contínuo de nominalização (Fairclough, 2001, p. 227), de tradução de uma gama de coisas do mundo, da atividade laboral à vida cotidiana, para o seu campo semântico. Um aspecto desse fenômeno, relacionado aos objetivos deste trabalho, é a construção do imaginário em torno do país empreendedor, o que se relaciona com o Brasil, mas também com uma série de outros países, alinhados com o sistema capitalista e com o mercado neoliberal. Como diz Hernán Cheyre (2013, p. 37, tradução nossa), vice-presidente executivo da CORFO - Corporación de Fomento de laProducción do Chile, "a cultura do empreendedorismo é a cultura do esforço, da superação 
e da perseverança"7. Sua publicação é uma análise sobre o avanço da atividade produtiva naquele país e o papel do empreendedorismo, incentivado pelo Estado, a permitir "a liberação da força criadora das pessoas através do empreendedorismo" (Fairclough) . $^{8}$

A questão motivacional que envolve a cultura empreendedora, evidenciada na definição apresentada por Cheyre, alcança níveis hiperbólicos na publicação Portugal Empreendedor (Jardim e Franco, 2014). Como é expresso logo na introdução, o objetivo da obra é "promover, pelo confronto com figuras inspiradoras de empreendedores que realizaram e realizam projetos significativos em diversos domínios da atividade humana, a educação para o empreendedorismo" (Introdução, p. 1). Para levar a cabo esse projeto, os autores se ancoram na releitura da história portuguesa pela ótica do empreendedor, ao assumirem um conceito abrangente de empreendedorismo, com destaque para o que denominam empreendedores sociais e culturais. Em outras palavras, os personagens modelares são "indivíduos que têm soluções inovadoras para problemas sociais emergentes", assim como os que apresentam "uma intervenção criativa no campo da cultura" (Introdução, p. 2) - sendo a cultura vista também em sentido amplo, como produção do humano nas suas mais diversas formas.

Com o objetivo de promover a inteligência empreendedora entre os portugueses, Jardime Franco se valem da popularização de biografias, bem como do incentivo a autobiografias (gêneros incluídos na noção de espaço biográfico de Arfuch, 2010), para inspirar novos empreendedores. Nesse projeto de nação empreendedora, a construção da historicidade vai estabelecer como marco zero das figuras empreendedoras históricas o exemplo de D. Alfonso Henriques (c.1109-1185), agora intitulado o fundador empreendedor. O primeiro rei de Portugal foi responsável, entre outros feitos, pela consolidação da "identidade psicológica da marca Portugal" (p. D. ${ }^{9}$ ). Nesse percurso desenvolvido pelo livro, deparamo-nos com figuras como D. Isabel de Aragão (c.1269/70-1336), a Rainha Santa, empreendedora da paz e da solidariedade, definida como empreendedora social pela fundação de hospitais, hospício e albergarias. Ou ainda o Infante D. Henrique (1394-1460), precursor da era das grandes navegações portuguesas,

7 No original: "la cultura delemprendimiento es la cultura delesfuerzo, de lasuperación y de laperseverancia".

8 No original: "laliberación de lafuerzacreadora de las personas a través delemprendimiento".

9 As referências às páginas da obra Portugal Empreendedor (Jardim e Franco, 2014), contidas neste parágrafo, seguem o padrão da publicação em e-book, dividida em capítulos com numeração específica para cada um deles. 
denominado "empresário e estratégia da globalização portuguesa", ou "talvez a figura empreendedora mais mitificada de nossa história" (p. InfanteD.1).

É inegável que temos, especialmente no caso da obra Portugal Empreendedor, a constituição de modelos de cultura (Morin, 2007, p. 83); o que significa o estímulo a formas de projeção-identificação, com o objetivo de transformar o espírito do país. De acordo com Morin, enquanto o processo de identificação busca o equilíbrio entre "realismo e idealização" (p. 82), com a verossimilhança necessária para se estabelecer paralelos com a vida cotidiana da audiência, a projeção é mobilizada pelo imaginário, pelas aspirações mais elevadas que buscam estimular o sonho de si em outro plano, o patamar dos heróis olimpianos (p. 105-109).

Essa mesma estratégia de projeção-identificação no contexto português pode ser verificada em diversas palestras do TEDxO'Porto. No evento independente realizado na cidade do Porto relacionado com o TED Talks global, citamos um proeminente empreendedor-orador do cenário português, por seus discursos inflamados para motivar o empreendedorismo no país. Na edição de 2012, Miguel Gonçalves, em sua apresentação intitulada Haja novamente navegadores em Portugal (Gonçalves, 2012), lança a figura do empreendedor a um patamar épico, estabelecendo a conexão com os obstáculos e conquistas dos portugueses na era das grandes navegações. No cenário de crise da sociedade portuguesa, que ultrapassa a situação econômica e invade a autoestima de um povo, olhar para o passado e buscar resquícios de uma era gloriosa não deixa de ser um exercício de saudade, mas é principalmente um projeto motivacional, que busca configurar discursivamente a alma portuguesa para os tempos presente e futuro, do mercado como o mar a ser conquistado.

Essa breve reflexão sobre o contexto português, que é um dos cenários da pesquisa que realizamos desde 2013, serve como introdução à discussão que faremos sobre o imaginário da sociedade empreendedora e seus modelos de cultura, suas figuras e realizações exemplares, que buscam constituir um outro país. Um Brasil empreendedor, apresentado pelo Projeto Draft.

\section{Análise discursiva do Projeto Draft}

Segundo Ehrenberg (2010, p. 13), o empreendedor foi alçado ao plano de modelo de vida heroica de nosso tempo, uma vez que "[...] ele resume um estilo de vida que põe no comando a tomada de riscos numa sociedade que faz da concorrência interindividual uma justa competição". Apresentado como modelos de cultura, como exemplos de sucesso, o empreendedor e o empreendedor social, entre outras variantes do espectro abrangente derivado 
da cultura empreendedora, têm sua condição de vencedores traduzida por uma retórica visual bem definida. Uma visada geral da sucessão de postagens da plataforma Draft traduz essa condição a partir do sorriso, da feição descontraída e ao mesmo tempo determinada, da convicção e da realização. Uma retórica da felicidade, como representação do sucesso, é deduzida da galeria de rostos sorridentes dos empreendedores apresentados pelo Projeto, nas fotografias que acompanham cada história de projetos e pessoas. Como aponta Freire Filho (2010, p. 17), "[...] apóstolos da autoajuda, gurus espirituais, terapeutas alternativos e expertsem relações humanas não são, todavia, os únicos obcecados em iluminar o caminho para a felicidade". Estabelecida como imperativo, a felicidade no Draft é apresentada pela ótica da sociedade empreendedora, em variantes que vão do trabalho pelo bem comum, para mudar o mundo (função especialmente atribuída, mas não restrita, aos empreendedores sociais), à capacidade de atuar e vencer no mercado competitivo, a partir da concepção de novos negócios. Em ambos os aspectos citados, o sujeito é o ponto de partida, e a questão do imaginário da técnica é deslocado da materialidade dos aparatos tecnológicos para a técnica empreendedora. Trata-se de um Olimpo (no sentido de Morin, 2007), constituído por gente que faz. A alusão à clássica campanha publicitária do banco Bamerindus, que fez sucesso nos anos 1990, não é aleatória; identificamos nesses dois lugares, a campanha do Bamerindus e o Projeto Draft, a mesma disposição de apresentar um país de empreendedores, de makers (como é dito na apresentação do Draft), como modelos de cultura e, simultaneamente, como histórias de vida e trabalho exemplares, no sentido da discussão travada por Buonanno (2011). Os heróis de todos os dias, no mundo concebido pela cultura empreendedora.

Taylor (2010, p. 12) tem como hipótese central de seu trabalho a existência de uma "nova concepção de ordem moral da sociedade", derivada da modernidade ocidental. A ordem moral que passa a constituir o imaginário social de nosso tempo é resultante da consolidação de formas sociais que caracterizam a modernidade, como "[...] a economia de mercado, a esfera pública e o autogoverno das pessoas, entre outras" (Taylor). Como destaca o autor, "[...] a modernidade é também o nascimento de novos princípios de socialidade" (p. 26); considerando-se que vivemos numa era tributária do espírito da modernidade, concebemos a leitura do Projeto Draft como uma estratégia, arraigada nesse espírito, de planejar um mundo ordenado em função de uma moral empreendedora. A questão é que, de alguma forma, esse imaginário social se difunde como um paradigma geral, para além da prática empreendedora; parece estabelecer a socialidade dele derivado como uma 
divisão de mundo entre empreendedores no papel de lideranças, os liderados que são essenciais, porém secundários nessa constituição de mundo - a organização como um conjunto de trabalhadores, de voluntários, de sujeitos engajados, parece ser algo que só tem valor quando legitima uma liderança chancelada por essa sociedade empreendedora. À parte desse mundo ideal, estão os não-empreendedores, aqueles que escapam a essa ordem moral, que negam esses valores e essa disposição para empreender e simplesmente não ocupam espaço nesse território, nessa plataforma que reorganiza o país - ou são constituídos como alteridade, como aquilo que deve ser superado, evitado, destruído (no sentido da noção de disrupção, que discutimos a seguir).

Há uma lógica higienizadora implícita nesse ecossistema em que todos devem ser empreendedores, de projetos ou de si mesmo como projeto, transformado para atender a um ideal - de performance, de felicidade, de enquadramento em práticas e comportamentos legitimados por esse universo organizado. Essa concepção de país e as formas de trabalho, de socialidade, de visão de mundo enfim, estão alinhadas com a noção de imaginário social (Taylor, 2010). Para Taylor, o imaginário social incorpora um conjunto de expectativas que temos em relação ao outro, que envolve um grau de normatividade: "[...] nesta compreensão das normas está implícita a capacidade de reconhecer casos ideais [...]. E para lá do ideal, existe alguma noção de uma ordem moral ou metafísica, em cujo contexto as normas e os ideais ganham sentido" (p. 32). Há, dessa forma, uma relação intrínseca entre as práticas e a compreensão que lhes atribui sentido, que resulta num "mapa implícito do espaço social, dos tipos de pessoas a que nos podemos associar em que modos e em que instâncias"(p. 33).

No caso do Projeto Draft, além dos empreendedores destacados como modelos de sucesso, há espaços que caracterizam certa pedagogia para esse mundo, uma prescrição para enquadramento à ordem empreendedora. Como no projeto contemplado na publicação do dia 1 de novembro de 2014, o Projeto Happyplaces, cujo título é uma convocação à felicidade: Você já encontrou seu espaço no mundo? Que tal criá-lo?. Há um jogo curioso nessa proposta de incentivo à busca pela sua felicidade, pela via do empreendimento. A ordem moral se ancora na técnica, sendo ambos indissociáveis nessa concepção de mundo celebrada pelo Draft.

Há um caráter metalinguístico interessante que parte do próprio nome do projeto: a tradução da palavra draft traz sinônimos como: esboço, rascunho, desenho, anteprojeto. Ou seja, elementos que compõem o projeto, versões preliminares, esboços de uma sociedade em construção. Para atingir seus objetivos, há uma dimensão pedagógica para inclusão nesse universo 
empreendedor, por meio de postagens que trazem reflexões mais amplas sobre os temas correlatos a esse mundo, organizados na seção Seleção Draft. Alguns exemplos de temas dessa seleção: futuro; robôs; empregos do futuro; co-workers (ou novas concepções do trabalho em espaços e ações coletivas); carros compartilhados; The communication (r)evolution; soluções inovadoras para cidades; sustentabilidade; millenials (ou a chamada Geração Y); bitcoin humanitária (moedas alternativas ajustadas a projetos sociais); favela criativa; inovações; Brasil maker - retrato de uma nova geração de inovadores.

Ainda sobre a abordagem pedagógica da sociedade empreendedora, há a seção Verbete Draft, uma série mais recente, inaugurada no dia 11 de fevereiro de 2015, com o termo disrupção, sucedido em 18 de fevereiro pelo verbete inovação radical. Essa é uma série que se propõe a esclarecer os termos que correspondem à Nova Economia, como anunciam: uma economia empreendedora, conexionista, inserida na visão da expansão da inovação disruptiva no Brasil, como revela o texto que apresenta a missão do projeto (Projeto Draft, 2014). Uma economia de transformadores obcecados pela missão de inventar o futuro. Tanto os termos criados por essa cultura como a utilização constante de palavras na língua inglesa, incorporadas a essa espécie de esperanto empreendedor, remetem à lógica de uma novilíngua, uma linguagem que corresponde a uma cultura comum, de um grupo específico da sociedade (os empreendedores, os inovadores, os makers), mas que pretende se imporem um espectro mais amplo, estabelecendo uma nova cultura também fundada em processos comunicacionais. Alguns termos são onipresentes nessa plataforma Draft, entre eles o verbo transformar e suas variantes, acompanhado na maioria das vezes pelo termo mundo. Eis uma marca discursiva que representa o desejo pela universalidade, pela amplificação da ideologia do empreendedorismo para a sociedade como um todo. Trata-se de uma linguagem que oscila entre a globalidade e a setorização.

Voltemos à questão da disrupção, que se apresenta como noção central, norteadora do projeto concebido pelo Draft. Na postagem de 11 de fevereiro sobre o termo (Blanco, 2015), apresenta-se o que seria sua definição e fundamentação teórica, com ancoragem retórica no campo acadêmico. A partir da negativa de que esse termo seria sinônimo de qualquer coisa que seja associada à inovação, ao moderno, usado como um jargão autocongrulatório[sic], defende-se a noção de que se trata de "produto ou serviço que cria um novo mercado e desestabiliza os concorrentes que antes o dominavam. É geralmente algo mais simples, mais barato do que o que já existe, ou algo capaz de atender um público que antes não tinha acesso ao mercado"(Blanco, 2015). Atribuído a 
Clayton Christensen, professor de Harvard, o conceito seria inspirado na noção clássica de destruição criativa de Schumpeter, e que fundamentaria a leitura de que as revoluções industriais e tecnológicas acabam por destruir o que havia anteriormente para tomar seu mercado.

Sem adentrarmos o campo movediço da discussão econômica sobre o termo disrupção - que o próprio Draft demonstra sofrer questionamentos em sua fundamentação e demonstrações empíricas - ficamos com a leitura adotada pelo Draft como inspiração para sua concepção de Nova Economia:

\begin{abstract}
Para explicar a seguinte teoria: quando uma empresa lança uma tecnologia mais barata, acessível e eficiente, mirando margens de lucros menores, cria uma revolução. Deixa obsoleto quem antes era líder de mercado. É o oposto do que Christensen chama de"Inovações sustentáveis" - as que não chegam a criar um novo mercado e concorrem com outras empresas de forma mais tradicional (Blanco, 2015).
\end{abstract}

Esse núcleo ideológico leva à compreensão mais densa do projeto de sociedade imaginado pelo Draft: seria o esboço de um novo mundo concebido como um mercado renovado, com novos players, que destrói tudo que havia anteriormente. Essa destruição criativa seria levada a cabo em nome do empoderamento (empowerment, no original) do consumidor: "as inovações disruptivas dão mais informação e poder de escolha ao consumidor, facilitam processos e barateiam produtos, que assim se tornam acessíveis a mais gente"(Blanco, 2015). Como efeitos colaterais assumidos, mas não vistos como algo que prejudique o mundo, estão: demissões de milhões de pessoas, falências de empresas ou quedas drásticas de lucros, diante da concorrência revolucionária.

Koselleck considera que "[...] a batalha semântica para definir, manter ou impor posições políticas e sociais em virtude das definições está presente, sem dúvida, em todas as épocas de crise registradas em fontes escritas". Aponta ainda que, após a Revolução Francesa, essa batalha se intensifica e se modifica, uma vez que "[...] os conceitos não servem mais para apreender os fatos de tal ou tal maneira, eles apontam para o futuro" (Koselleck, 2006, p. 102). Nesse sentido se estabelece o imaginário da utopia pragmática do Draft, uma vez que se imagina um lugar futuro, a partir da celebração da revolução identificada 
no presente. A gente que faz que habita seu território simbólico representaria a liderança do país futuro, imaginado pela técnica empreendedora? Talvez aí se explique o destaque para os jovens empreendedores, a preocupação reiterada com a geração Millenials, discutida em mais de um tópico. Sua imagem é recorrente nesse cenário, a começar pelos projetos de empreendedorismo social como o Atados (atados.com.br), apresentado no Draft em 18/2/15, e que objetiva estabelecer a conexão entre projetos de cariz social e o voluntariado. Tendo como lema uma rede do bem, para fazer o bem!,sua concepção traduz o imaginário do jovem-ponte, figura celebrada como agente da mudança do país na pesquisa Sonho Brasileiro (2011) da agência Box1824, e que guarda plena identidade com o homem conexionista, associado ao novo espírito do capitalismo, que discutimos anteriormente.

A contribuição de Koselleck sobre a história dos conceitos oferece pistas valiosas para compreender o que está em jogo nesse processo de ressignificação promovido pelo Projeto Draft, como representante de uma cultura mercadológica que ambiciona se renovar - no sentido da renovação cíclica da retórica capitalista discutida por Boltanski e Chiapello (2009). A começar pela noção de transformação, articulada com o conceito de revolução - que foi um dos objetos de análise do autor. Nesse sentido, “[...] o uso e a extensão do termo [revolução] são variáveis, do ponto de vista linguístico" (Koselleck, 2006, p. 61); essa espécie de conceito geral sofre variações drásticas de um contexto a outro; “[...] é quase como se no interior da palavra revolução habitasse uma força revolucionária capaz de fazer com que a expressão se dissemine continuamente e seja capaz de conter em si o mundo todo" (Koselleck, 2006, p. 62). Somente nessa mutação contínua é possível apreender o que se julga por revolução, por processo de transformação alardeado pelo Projeto Draft.

A inovação disruptiva abarca a ideia de revolução, restringindo-a à prática empreendedora, ao mercado como entidade totalizante, que tudo comporta. É curioso perceber o acúmulo de paradoxos que esse conceito norteador proporciona, quando se observa os casos e exemplos apresentados como modelares. Há uma profusão de histórias de negócios que compõem uma narrativa de vida de transformação, como se o sujeito revolucionasse a si mesmo, e por consequência pudesse mudar o mundo. Algo que guarda relação com o con- 
ceito de narrativas terapêuticas desenvolvido por Illouz (2011). Como é o caso da executiva de bancos de investimentos "e também ativista" Cristiane Pedote (Vieira, 2015), despertada para outra realidade para além do mercado financeiro por meio de um convite de seu filho:

Em 2011, depois de receber um convite do filho mais velho, Lucas, passou dois dias dormindo no chão de uma escola pública para construir uma casa para uma família carente. "A sensação que tive quando voltei para o meu lar foi quase como se estivesse num portal, numa outra dimensão. Fiquei muito abalada. Foi aquele choque entre estar na miséria e, de repente, estar no conforto, e pensei: 'Só posso estar vivendo num outro planeta"', conta (VIEIRA, 2015).

A experiência que promove um turning point na trajetória de vida faz com que ela renove seu olhar, mas a disrupção é basicamente um despertar para novos negócios, para oportunidades de se recolocar no mercado com outra visão de suas funções - a ideia do trabalho com propósito, diretamente relacionada com a Geração Y, é retomada de forma recorrente. A Nova Economia apregoada pelo Projeto Draft é composta por empreendimentos que têm como objetivo atender problemas sociais - sobre os quais paira a aura do sacrifício do herói em prol do bem comum -, mas também por ideias revolucionárias para produzir lucro, unindo negócios com o chamado propósito. Como se pode perceber no projeto Tem Açúcar? (Diniz, 2015), que se propõe como uma "plataforma para facilitar doações e empréstimos entre vizinhos". A startup, que apoia sua ideia nas formas de sociabilidade em torno das práticas de consumo, é apontada como possível solução de "boa parte das necessidades do cotidiano - e, quem sabe, para alguns problemas graves do planeta":

Engajamento ela já conseguiu. Gente disposta a participar, também. Dinheiro, ainda não. Ainda que o futuro do negócio seja incerto. $\mathrm{A}$ aposta da Tem Açúcar envolve uma transformação cultural. Camila sabe que isso não acontece da noite para o dia, mas sabe também que empreender é acreditar em uma boa ideia e bancar seus riscos (DINIZ, 2015).

O conceito de engajamento, fundamental na teoria do novo espírito do capitalismo, torna-se explícito no texto sobre o projeto Tem Açúcar? bem como a sua condição de novo negócio, que ambiciona criar um novo mercado resultante de uma transformação cultural, ou seja, de mudanças de práticas de consumo individualizadas para uma cultura coletiva de empréstimos, mediada 
pela plataforma do projeto. Eis que encontramos, de forma nítida, o paradoxo apontado por Boltanski e Chiapello (2009) sobre o mundo conexionista e sua forma de mercantilizar as relações. A solução de problemas graves do planeta, pela formação discursiva, é praticamente um efeito colateral, uma consequência quase improvável do sucesso do empreendimento. O empreendedor se coloca no lugar de liderança, mas seu projeto de transformação da sociedade é, antes de tudo, um projeto de negócios, que mobiliza o sentido da mudança para encontrar seu lugar no mercado competitivo e predatório. Nas apresentações das histórias de sucesso, ou de ideias destacadas por seu potencial para promover a tal inovação disruptiva, temos um atravessamento entre histórias pessoais, narrativas fundadoras das organizações e projetos, diagnósticos da sociedade e projeções da mudança que se encaixam na visão de mundo da sociedade empreendedora. E, ao final de todas elas, está o Draft Card, um quadro que apresenta, de forma sintética, o nome e foco do projeto, sócios e número de funcionários, investimento inicial e faturamento, além dos contatos telefônico e digital. Um cartão de visitas para nos lembrarmos de que, para além da utópica visão de uma cultura cooperativa e colaborativa, a noção de rede no Projeto Draft se traduz no chamado networking - a oportunidade de novos negócios, de investidores, de colaborações das mais diversas, que resultem na produtividade mercadológica das conexões. O mundo conexionista, enfim, apresenta sua leitura de um novo mercado, em que a retórica do bem comum se torna um mote indissociável dos projetos, inovações, das narrativas de vida que se oferecem para o consumo simbólico como histórias exemplares, como modelos de cultura.

\section{Considerações finais}

Jameson, em sua obra Archaeologiesofthe future (2005), desenvolve a tese de que a utopia é, essencialmente, a realização de desejos coletivos ( $a$ collectivewish-fulfilment). O problema levantado pelo autor é que, em uma sociedade individualista como vivemos hoje, cada um imagina a realização da sociedade ideal de forma distinta, e cada utopia particular expressa posições ideológicas, aspectos relacionados a classes específicas. Apesar do impulso utópico, da mobilização da ideia de bem comum, há outras visões presentes na teia social, e os choques e disputas entre elas parece ser algo incontornável. Em outro aspecto, a pretensão da universalidade da sociedade empreendedora em parte atualiza a universalização do ideário burguês na consolidação do sistema capitalista, como bem discute Pesavento (1997, p. 15), em seu estudo 
sobre as Exposições Universais do século XIX. O imaginário burguês, segundo Pesavento, envolve uma dimensão intencional, um cálculo, ou ainda um projeto de sociedade em que as crenças e ideias são difundidas a partir da legitimidade de sua base concreta. No caso do Projeto Draft, essa dimensão supostamente verificável é oferecida pelo formato emprestado ao jornalismo digital, de noticiar os acontecimentos e personagens reais desse mundo em transformação. A galeria de exemplos serve à estratégia de convocação para o alinhamento dos sujeitos, consumidores simbólicos, a esse mundo editado.

Encontramos, no Draft, uma sucessão de casos, personagens, histórias, receitas de sucesso, apontamentos para uma ideia de futuro, apresentados como elos de uma mesma cadeia discursiva (Bakhtin, 2008), mas sem o caráter dialógico-polifônico da teoria bakhtiniana (1997), uma vez que a orquestração de vozes não apresenta dissonâncias, somente o jogo enunciativo de atribuir aos personagens e suas histórias a legitimidade para a tese que engloba a tudo e a todos nessa plataforma. Visto como um território que abarca uma imagem de multiplicidade de agentes, promove a simulação do movimento revolucionário que apregoa, a realização de um futuro sonhado pela sociedade empreendedora, que simultaneamente está acontecendo, aqui e agora. Nesse grande painel articulado pela noção de disrupção, todos são destruidores criativos, sejam aqueles engajados em empreendimentos sociais e causas associadas diretamente a uma noção de bem comum, sejam aqueles que rompem mercados e se impõem com seus novos negócios, ou que possuem esse objetivo como prioritário.

Há um contraste nítido entre a euforia hiperbólica do Draft em sua proposta de transformar o país e o mundo, e a condição específica dos projetos atomizados, as soluções particularizadas que representam os fragmentos desse projeto de sociedade - baseado na crença e no entusiasmo com a técnica empreendedora, porseus porta-vozes midiáticos. Práticas ediscursos (Fairclough, 2001) se imbricam e entram em choque, prevalecendo o tom motivacional e a estética da felicidade em torno da cultura maker como unidade, em meio às contradições do projeto. A incerteza do futuro que se refere ao projeto Tem Açúcar? é, em essência, o diagnóstico que podemos fazer ante a leitura do esboço de sociedade apresentado pelo Projeto Draft. Ficamos com uma questão em aberto, que não se resolve aqui: estamos diante de uma sociedade baseada no mercado, ou um mercado que se concebe como sociedade? 


\section{REFERÊNCIAS}

ALL WORK AND ALL PLAY. Vídeo de divulgação de pesquisa realizada pela agência Box1824, divulgado em 2012. Disponível em: <vimeo.com/44130258>. Acesso em: 20 nov. 2015.

ARFUCH, Leonor. O espaço biográfico: Dilemas da subjetividade contemporânea. Rio de Janeiro: EdUERJ, 2010.

BAKHTIN, Mikhail (Bajtín). Estética de la creación verbal. Buenos Aires: Siglo XXI, 2008.

. (Voloshinov). Marxismo e filosofia da linguagem. São Paulo: Hucitec, 1997.

BLANCO, Gisela. Verbete Draft: o que é disrupção? Projeto Draft, 11 fev. 2015. Disponível em: <http://projetodraft.com/verbete-draft-o-que-e-disrupcao/.>. Acesso em: 6 abr. 2016.

BOLTANSKI, Luc; CHIAPELLO, Ève. O novo espírito do capitalismo. São Paulo: Martins Fontes, 2009.

BUONANNO, Milly. Histórias de vida exemplares. Biografias. MATRIZes, ano 5, n.1, p. 63-84, 2011.

CASAQUI, Vander. A invenção de um país de empreendedores sociais: "Imagina na Copa" e seu projeto de Brasil. In: Anais do $23^{\circ}$ Encontro Anual da Compós. Belém - Pará: UFPA, p. 1-19, 2014.

CHEYRE V, Hernán. Construyendo un país de emprendedores. Santiago de Chile: Ediciones LYD, 2013.

DAHRENDORF, Ralf. Homo sociologicus. Lisboa: Quetzal, 2012.

DINIZ, Leticia.Tem açúcar, boa vizinhança e colaboração: como um site está resgatandoo hábito de pedir emprestado. Projeto Draft, 26 jan. 2015. Disponível em: $<\underline{\text { http:// }}$ projetodraft.com/tem-acucar-tem-boa-vizinhanca-e-tem-colaboracao-comoum-site-esta-resgatando-o-costume-de-pedir-emprestado/>. Acesso em: 6 abr. 2016.

DRUCKER, Peter F. Inovação e espírito empreendedor: Prática e princípios. São Paulo: Cengage Learning, 2011.

EHRENBERG, Alain. $\mathbf{O}$ culto da performance: da aventura empreendedora à depressão nervosa. Aparecida - SP: Idéias \& Letras, 2010.

FAIRCLOUGH, Norman. Discurso e mudança social. Brasília: UNB, 2001.

FREIRE FILHO, João (org.). Ser feliz hoje: Reflexões sobre o imperativo da felicidade.

Rio de Janeiro: FGV, 2010. 
GONÇALVES, Miguel. Haja novamente navegadores em Portugal (apresentação no TEDxO'Porto de 2012). Disponível em: <https://www.youtube.com/ watch?v=VoqO9DyAEQ4>. Acesso em: 20 nov. 2015.

ILLOUZ, Eva. O amor nos tempos do capitalismo. Rio de Janeiro: Zahar, 2011.

JAMESON, Fredric. Archaeologies of the future: The desire called utopia and other science fictions. London, New York: Verso Books, 2005.

JARDIM, Jacinto; FRANCO, José E. (orgs.). Portugal empreendedor: Trinta figuras empreendedoras da cultura portuguesa - relevância dos modelos para a promoção do empreendedorismo. Lisboa: INCM, 2014 (ebook).

KOSELLECK, Reinhart. Futuro passado: Contribuição à semântica dos tempos históricos. Rio de Janeiro: Contraponto, 2006.

MORIN, Edgar. Cultura de massas no século XX - v. 1, Neurose. Rio de Janeiro: Forense Universitária, 2007.

PESAVENTO, Sandra J. Exposições universais: Espetáculos da modernidade do século XIX. São Paulo: Hucitec, 1997.

PRADO, José L. Aidar. Convocações biopolíticas dos dispositivos comunicacionais. São Paulo: Educ / Fapesp, 2013.

PROJETO DRAFT. Missão. Projeto Draft, 2014. Disponível em: $\leq$ http://projetodraft. com/o-que-queremos/>. Acesso em: 6 abr. 2016.

. Vídeo de divulgação veiculado em 2013. Disponível em: <https://www. youtube.com/watch?v=7ZvPkWenZOA>. Acesso em: 15 nov. 2015.

PROJETO SONHO BRASILEIRO. Pesquisa realizada pela agência Box1824, divulgada em 2011. Disponível em: <http://pesquisa.osonhobrasileiro.com.br/indexn.php>. Acesso em: 7 fev. 2015.

SARLO, Beatriz. La imaginación técnica: Sueños modernos de la cultura argentina. Buenos Aires: Nueva Visión, 2004.

TAYLOR, Charles. Imaginários sociais modernos. Lisboa:Texto \& Grafia, 2010.

VIEIRA, Aline. Como Cristiane Pedote usa seu poder em uma gigante financeira para ajudar a mudar o mundo. Projeto Draft, 27 jan. 2015. Disponível em: $\leq$ http:// projetodraft.com/como-a-executiva-cristiane-pedote-45-usa-seu-poder-emuma-gigante-financeira-para-ajudar-a-mudar-o-mundo/>. Acesso em: 6 abr. 2016.

WEBER, Max. A ética protestante e o"espírito" do capitalismo. São Paulo: Companhia das Letras, 2004 [1905]. 
Recebido em: 10/12/2015

Aceito em: 5/1/2016

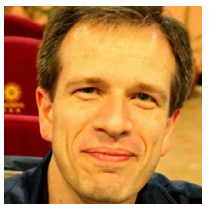

Endereço do autor:

Vander Casaqui <vcasaqui@yahoo.com.br>

http://lattes.cnpq.br/0880498948493745

Programa de Pós-Graduação em Comunicação e Práticas de Consumo da Escola Superior de Propaganda e

Marketing (ESPM)

Rua Dr. Álvaro Alvim, 123

04018-010 - Vila Mariana - São Paulo - SP - Brasil 